\title{
Report on Oak Ridge National Laboratory Testing of Ambient Cure TransPowr E3X ${ }^{\circledR}$
}

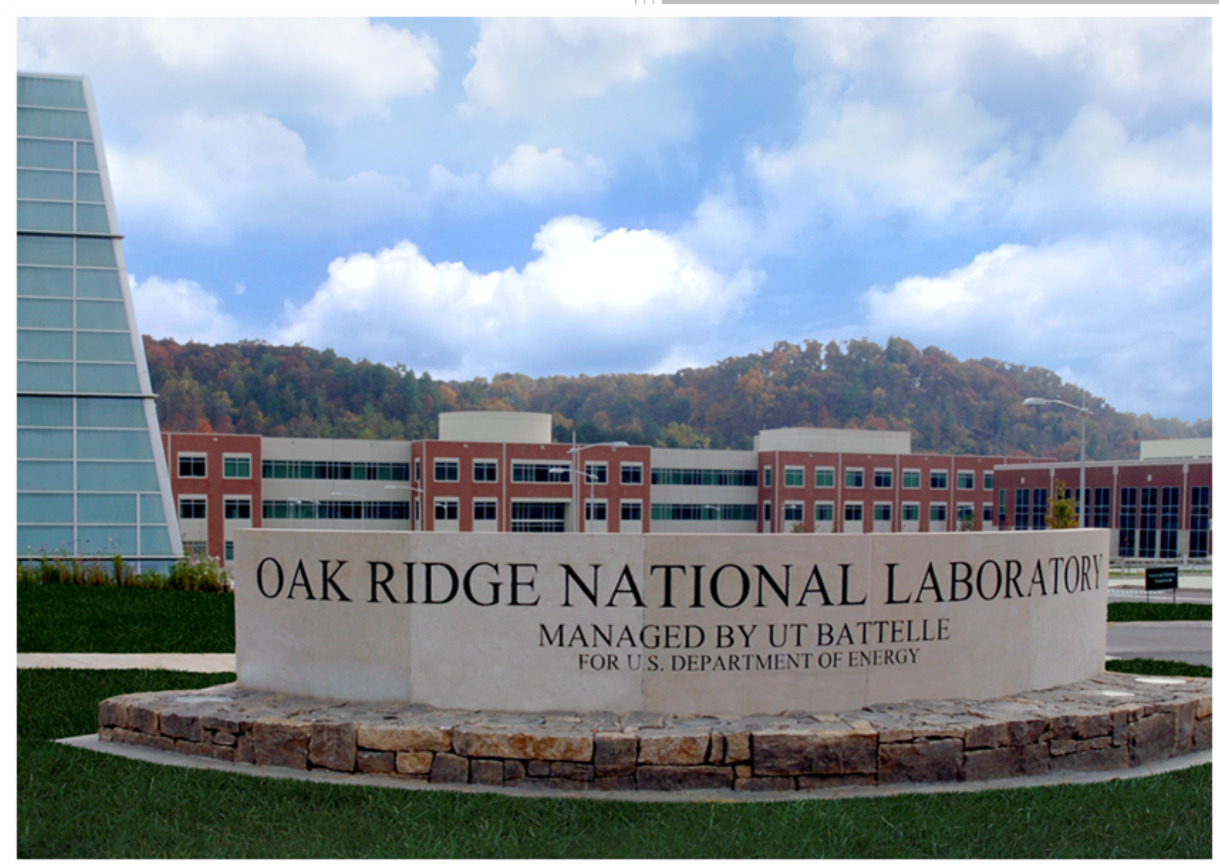

Philip Irminger

Dan King

Drew Herron

Zhi Li

Gordon Baker

Timothy Ochmann

Phil Overholt

April 2020 


\title{
DOCUMENT AVAILABILITY
}

Reports produced after January 1, 1996, are generally available free via US Department of Energy (DOE) SciTech Connect.

\section{Website http://www.osti.gov/scitech/}

Reports produced before January 1, 1996, may be purchased by members of the public from the following source:

\author{
National Technical Information Service \\ 5285 Port Royal Road \\ Springfield, VA 22161 \\ Telephone 703-605-6000 (1-800-553-6847) \\ TDD 703-487-4639 \\ Fax 703-605-6900 \\ E-mailinfo@ntis.gov \\ Website http://www.ntis.gov/help/ordermethods.aspx
}

Reports are available to DOE employees, DOE contractors, Energy Technology Data Exchange representatives, and International Nuclear Information System representatives from the following source:

Office of Scientific and Technical Information

PO Box 62

Oak Ridge, TN 37831

Telephone 865-576-8401

Fax 865-576-5728

E-mail reports@osti.gov

Website http://www.osti.gov/contact.html

This report was prepared as an account of work sponsored by an
agency of the United States Government. Neither the United States
Government nor any agency thereof, nor any of their employees, makes
any warranty, express or implied, or assumes any legal liability or
responsibility for the accuracy, completeness, or usefulness of any
information, apparatus, product, or process disclosed, or represents that
its use would not infringe privately owned rights. Reference herein to
any specific commercial product, process, or service by trade name,
trademark, manufacturer, or otherwise, does not necessarily constitute
or imply its endorsement, recommendation, or favoring by the United
States Government or any agency thereof. The views and opinions of
authors expressed herein do not necessarily state or reflect those of the
United States Government or any agency thereof.


Electrical and Electronics Systems Research Division

\title{
REPORT ON OAK RIDGE NATIONAL
}

\section{LABORATORY TESTING OF AMBIENT CURE TRANSPOWR E3X ${ }^{\circledR}$}

\author{
Philip Irminger \\ Oak Ridge National Laboratory \\ Dan King \\ Oak Ridge National Laboratory \\ Drew Herron \\ Oak Ridge National Laboratory \\ Zhi Li \\ Oak Ridge National Laboratory \\ Gordon Baker \\ General Cable Corporation \\ Timothy Ochmann \\ General Cable Corporation \\ Phil Overholt \\ Department of Energy
}

Date Published: March 2020

Prepared by

OAK RIDGE NATIONAL LABORATORY

Oak Ridge, TN 37831-6283

managed by

UT-BATTELLE, LLC

for the

US DEPARTMENT OF ENERGY

under contract DE-AC05-00OR22725 



\section{CONTENTS}

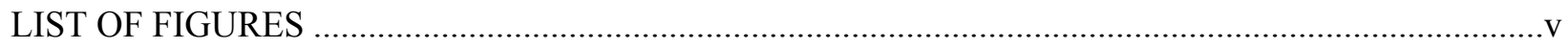

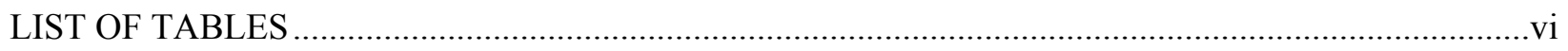

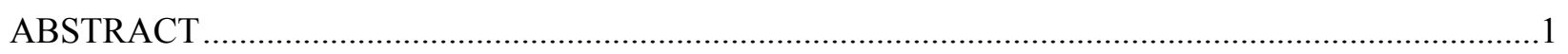



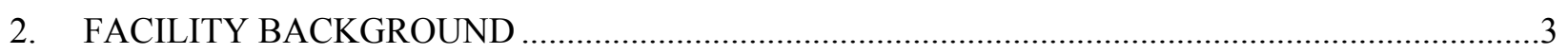



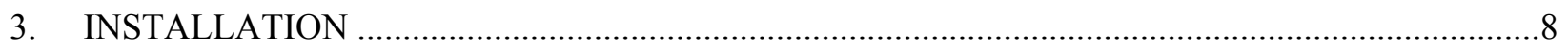

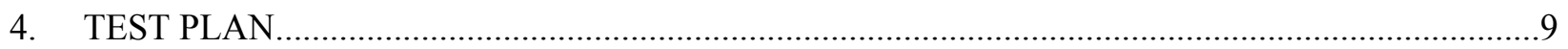

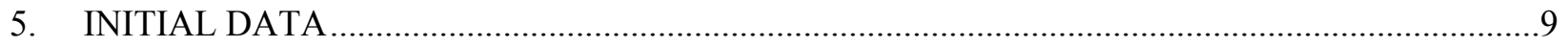

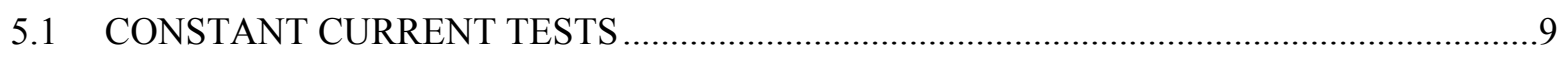

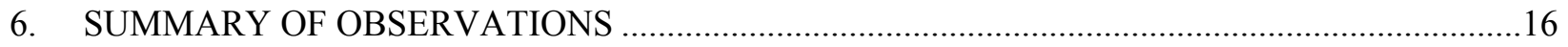

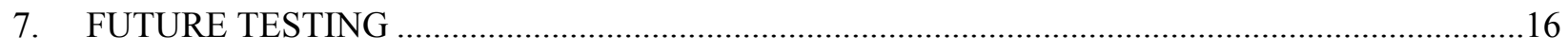

APPENDIX A. CONTROL SYSTEM FOR THE POWERLINE CONDUCTOR ACCELERATED TEST FACILITY ...................................................................

APPENDIX B. THERMOCOUPLE CHANNELS AND LOCATIONS ............................................... 



\section{LIST OF FIGURES}

1. E3X Technology features a high emissivity, low absorptivity surface coating applied to

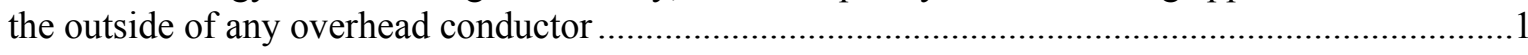

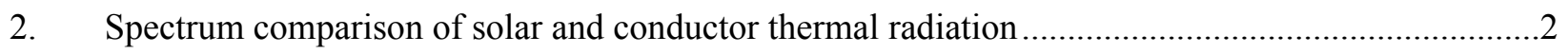



4. Increased operating temperatures of high temperature, low sag conductors.................................... 3

5. Aerial view of the Powerline Conductor Accelerated Test facility .................................................

6. Graphical depiction of the Powerline Conductor Accelerated Test facility



7. Graphical depiction of the Powerline Conductor Accelerated Test facility

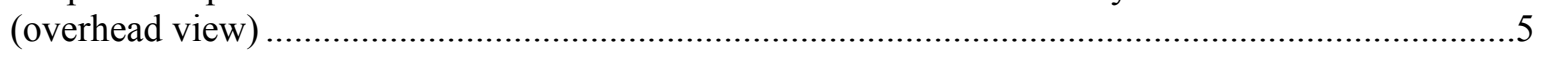

8. Drake/ACSS/MA2/E3X and Drake/ACSS/MA2 _..................................................................6

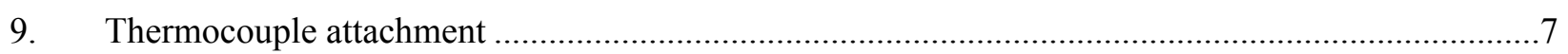

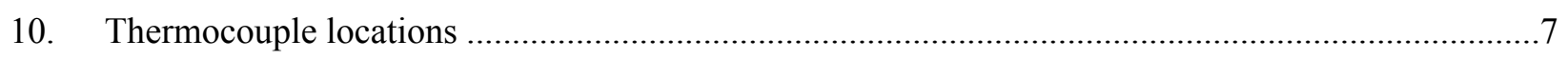



12. Pay-off reel brake failure caused the Drake/ACSS/MA2/E3X conductor to

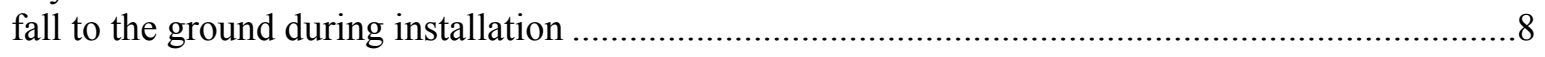

13. Temperature comparison of Drake/ACSS/MA2 and Drake/ACSS/MA2/E3X at $650 \mathrm{~A}$

14. Temperature comparison of Drake/ACSS/MA2 and Drake/ACSS/MA2/E3X at $500 \mathrm{~A}$

15. Temperature comparison of Drake/ACSS/MA2 and Drake/ACSS/MA2/E3X

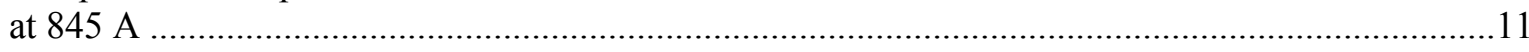

16. Temperature comparison of Drake/ACSS/MA2 and Drake/ACSS/MA2/E3X at $900 \mathrm{~A}$

17. Temperature comparison of Drake/ACSS/MA2 and Drake/ACSS/MA2/E3X at $1,030 \mathrm{~A}$

18. Temperature comparison of Drake/ACSS/MA2 and Drake/ACSS/MA2/E3X

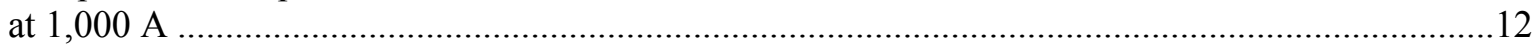

19. Temperature comparison of Drake/ACSS/MA2 and Drake/ACSS/MA2/E3X at $1,220 \mathrm{~A}$

20. Temperature comparison of Drake/ACSS/MA2 and Drake/ACSS/MA2/E3X



21. Temperature comparison of Drake/ACSS/MA2 and Drake/ACSS/MA2/E3X

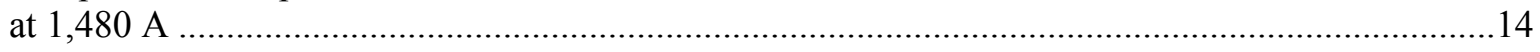

22. Temperature comparison of Drake/ACSS/MA2 and Drake/ACSS/MA2/E3X at $1,420 \mathrm{~A}$ and $1,575 \mathrm{~A}$

23. A reduction in sag (indicating lower temperature) can be seen on the Drake/ACSS/MA2/E3X conductor 


\section{LIST OF TABLES}



2. Initial Results of Constant Current Testing ..................................................................................15 


\begin{abstract}
A key to industry acceptance of a new technology is extensive validation in field trials. The Powerline Conductor Accelerated Test facility (PCAT) at Oak Ridge National Laboratory (ORNL) is specifically designed to evaluate the performance and reliability of novel overhead conductor and conductor instrumentation under field conditions. The facility is set up to capture large amounts of data during testing.
\end{abstract}

General Cable used the ORNL PCAT facility to validate the performance of TransPowr ${ }^{\circledR}$ with Ambient Cure E3X $\mathrm{X}^{\mathrm{TM}}$ Technology — a standard overhead conductor with a high emissivity, low absorptivity ambient cure surface coating. Extensive testing has demonstrated a significant improvement in conductor performance across a wide range of operating temperatures with respect to uncoated conductor of the same type, indicating that E3X Technology can provide a reduction in temperature, a reduction in sag, and an increase in ampacity when applied to the surface of any overhead conductor. This report provides results of that testing.

\title{
1. TECHNOLOGY BACKGROUND
}

Aluminum is the metal of choice for overhead transmission conductors due to its low electrical resistance, weight, and cost. However, aluminum has inherently low emissivity that causes overhead conductors to retain Joule heat generated during transmission of power. When overhead conductors operate at higher temperatures it leads to increased line power loss and conductor sag. The overhead conductor's available thermal rating is limited by aluminum's surface emissivity. Power losses in the United States from generation source to customer meter are estimated to be $6 \%$ or $\$ 20$ billion per year. Transmission and distribution overhead conductor line losses are the dominant source of these power losses.

One way to increase the efficiency of aluminum conductors is to increase their surface emissivity. General Cable's TransPowr with E3X Technology is an overhead conductor with a high-emissivity, low-absorptivity surface coating (Fig. 1). The use of this technology allows for achieving significantly lower operating temperatures

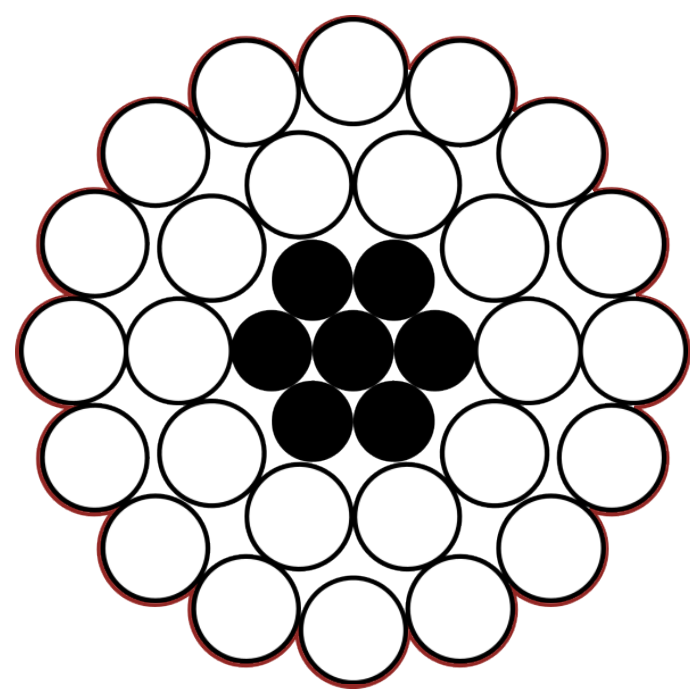

Fig. 1. E3X Technology features a high emissivity, low absorptivity surface coating applied to the outside of any overhead conductor. (Coating not to scale.) for the same current. This surface coating can be applied to all overhead conductors [e.g., all-aluminum (AAC); aluminum, steel-reinforced (ACSR); and aluminum, steel-supported (ACSS)] to provide a performance increase. The resulting conductors maintain the same benefits of the underlying technology but with improved heat dissipation for lower temperature and higher ampacity.

IEEE 738, defines the Standard for Calculating the Current-Temperature Relationship of Bare Overhead Conductors, the radiated heat loss is calculated by the Stefan-Boltzmann law and is dependent on the surface emissivity. 


$$
q_{r}=17.8 * D_{0} * \varepsilon *\left[\left(\frac{T_{s}+273}{100}\right)^{4}+\left(\frac{T_{a}+273}{100}\right)^{4}\right] W / m
$$

Equation 1. Radiated Heat Loss Equation, where $q_{r}$ is radiated heat loss, $D_{0}$ is conductor diameter, $\varepsilon$ is emissivity of the conductor, $T_{s}$ is conductor temperature, and $T_{a}$ is ambient temperature.

The solar heat gain is also provided and is dependent on the surface absorptivity.

$$
q_{s}=\alpha * Q_{s e} * \sin (\theta) * A^{\prime} W / m
$$

Equation 2. Solar Heat Gain Equation, where $q_{s}$ is solar heat gain, $\alpha$ is absorption coefficient, $Q_{s e}$ is total solar and sky radiated heat flux rate, $\theta$ is angle of incidence of sun's rays, and $A$ is conductor area.

Emissivity and absorptivity are equivalent at the same wavelength. However, overhead conductors emit thermal radiation at substantially different wavelengths than the sun does. E3X Technology takes advantage of this scientific phenomena by implementing a spectrally-selective surface coating that radiates heat (has high emissivity) in the far infrared region. This is where conductors radiate, and blocks heat absorption in the visible spectrum where the sun radiates (Fig. 2).

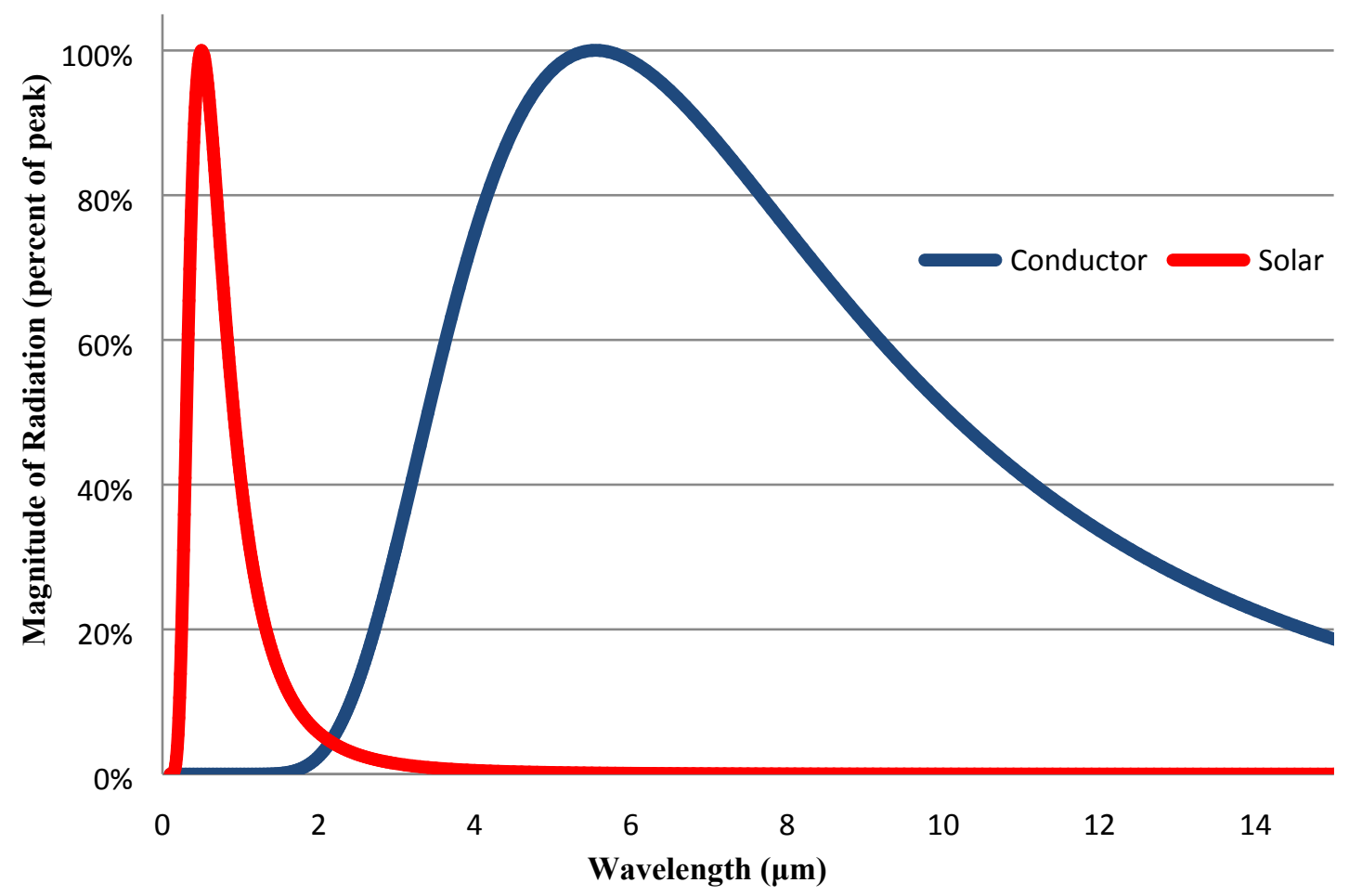

Fig. 2. Spectrum comparison of solar and conductor thermal radiation. (Magnitude expressed as a percentage of peak magnitude.)

Laboratory experiments show a 20\%-30\% reduction in temperature (in degrees Celsius) for the coated conductor when compared to uncoated conductors operating at the same ampacity and environmental conditions. In addition, a coated conductor affords approximately a $20 \%$ increase in ampacity when operating at the same temperature as an uncoated conductor. Because the coating is stable in the environment, E3X Technology is expected to provide a benefit for the lifetime of the conductor. 


\section{FACILITY BACKGROUND}

PCAT was developed by ORNL and the US Department of Energy (DOE) in 2003 as a test facility to evaluate the performance of novel overhead conductor designs. The objective of these novel conductors were to carry higher currents with the same or less sag in the conductor (Figs. 3 and 4).

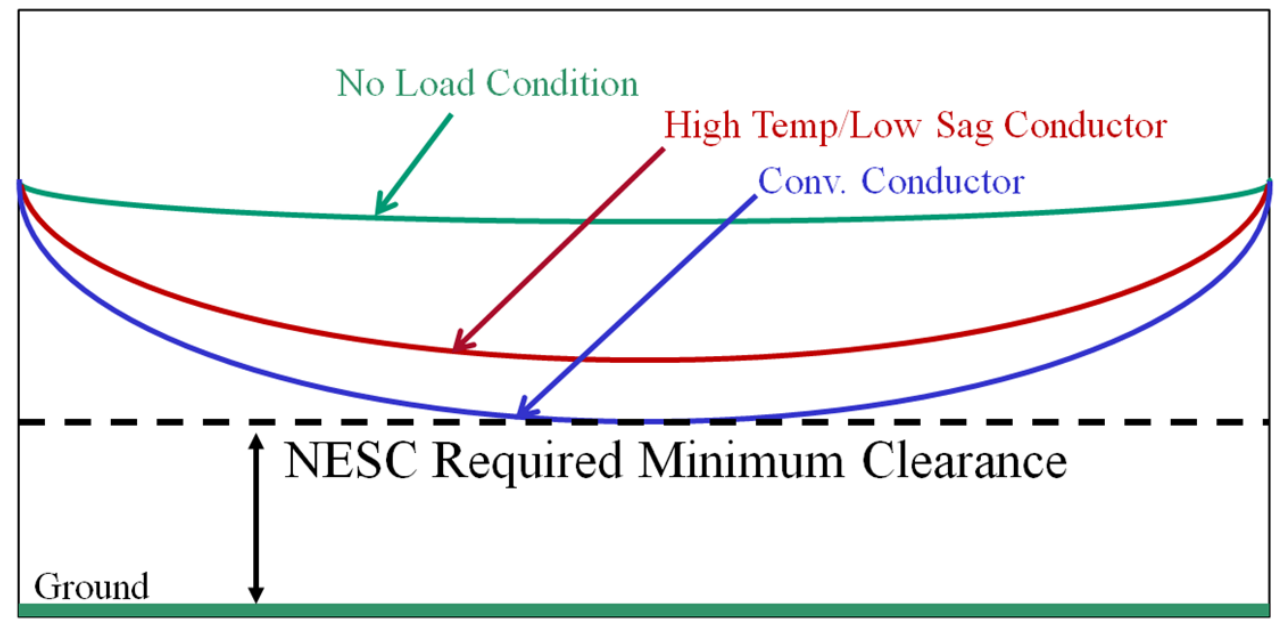

Fig. 3. High temperature, low sag conductors. $($ NESC $=$ National Electrical Safety Code.)

The facility was originally built to meet guidelines in the 2002 DOE National Transmission Grid Study, which stated that "DOE will develop national transmission-technology testing facilities that encourage partnering with industry to demonstrate advanced technologies in controlled environments. Working with TVA, DOE will create an industry cost-shared transmission line testing center at DOE's Oak Ridge National Laboratory (with at least a 50 percent industry cost share)."

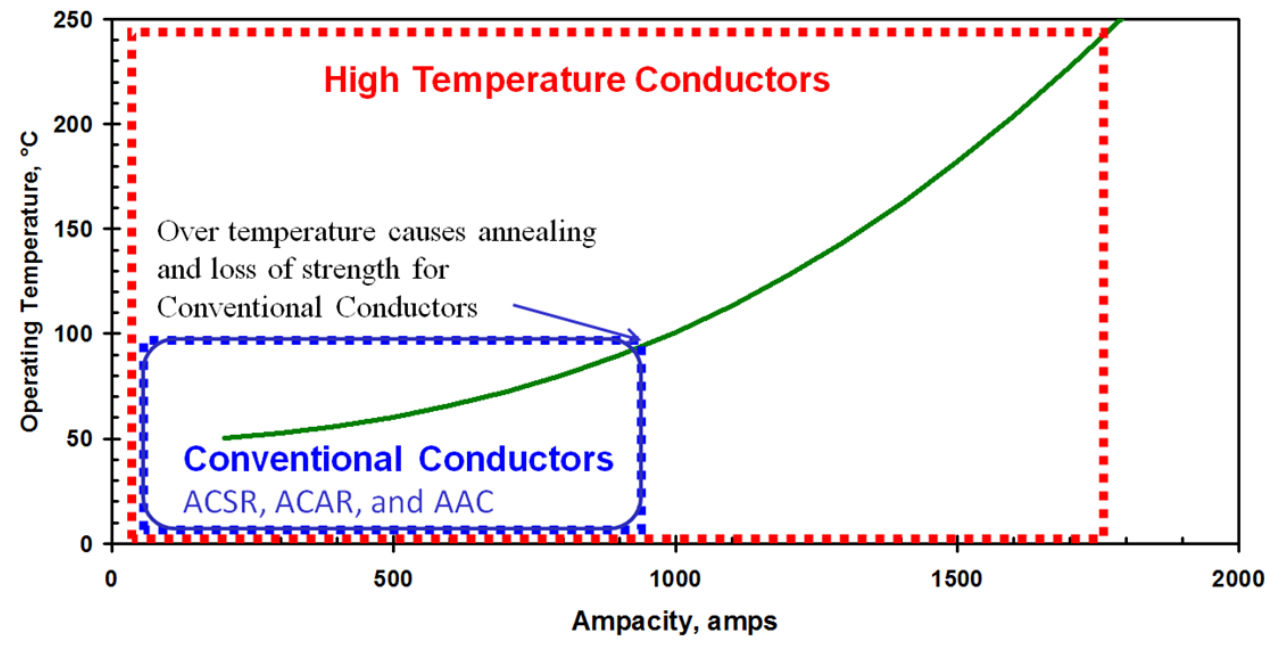

Fig. 4. Increased operating temperatures of high temperature, low sag conductors. (ACSR = aluminum conductor steel-reinforced, ACAR = aluminum cable alloyreinforced, and $\mathrm{AAC}=$ all-aluminum conductor.)

PCAT has been used to successfully field test overhead conductors and conductor instrumentation to demonstrate and validate performance in a real world environment either before or in conjunction with 
field trials. A big hurdle for utility acceptance of novel technologies is field evaluation, and PCAT is able to provide this performance validation through its real-world testing conditions where it is able the accelerate the aging on the conductor and test the lifetime.

PCAT is located at the ORNL campus in Oak Ridge, Tennessee (Fig. 5).

PCAT provides is a high-power, heavily instrumented and controlled, platform for performing performance testing of overhead conductors and conductor instrumentation. This includes collecting all the necessary information for overhead conductor characterization and characterization of whole systems, as well as splices and dead ends. The facility is part of a DOE effort to address growing demands for electric power at a time when existing transmission line capacity is nearing its limits. PCAT is also used to test advanced sensors and controls for overhead conductors.



Fig. 5. Aerial view of the Powerline Conductor Accelerated Test facility.

PCAT accommodates $2,400 \mathrm{ft}$ of overhead test conductor in a loop arrangement across two $600 \mathrm{ft}$ segments. The facility consists of five $161 \mathrm{kV}$-rated steel transmission poles that have extensive support to ensure mechanical stability, with two poles at each of the two dead ends and one in mid-span. The test line forms the load for the power supply by creating a loop and connecting its two ends to the two terminals of the power source. The power source is a controllable dc power supply that provides dc current up to 5,000 A (Figs. 6 and 7).



Existing 13-kV distribution line

Fig. 6. Graphical depiction of the Powerline Conductor Accelerated Test facility (side view). 
Total length $\sim 1300 \mathrm{ft}$.

DC

Prans- Power

Power Test conductors

former

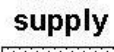

1

$50-80 \mathrm{ft}$

utility poles

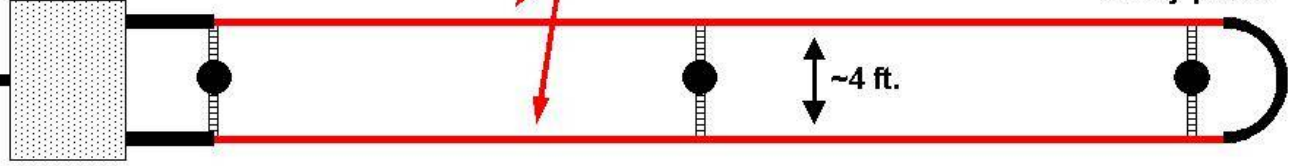

Test Line $=1200 \mathrm{ft} .(2-600 \mathrm{ft}$. spans $)$

Instrumentation shed

Existing communications line

(telephone or internet)

Existing 13.8-kV distribution line

Fig. 7. Graphical depiction of the Powerline Conductor Accelerated Test facility (overhead view).

Because all tests at PCAT are at relatively low voltage (typically less than $100 \mathrm{Vdc}$ ), it is possible to place extensive instrumentation in direct contact with the test conductors. Measurement capability at PCAT include surface and core temperatures of the conductor under test and simultaneous measurement of conductor voltage, current, tension, sag, and environmental conditions (e.g., wind, solar, ambient). A messenger line with fiber optic loops and a $120 \mathrm{~V}$ instrumentation line are available above the test line to provide control power and communication for instrumentation. (See Appendix A for more information on the PCAT control system and Appendix B for more information placement of thermocouples at PCAT for conductor surface and core measurements.)

\subsection{TEST HARDWARE}

The following overhead conductor hardware was used in the TransPowr with Ambient Cure E3X Technology testing.

- 795 kcmil Drake/ACSS/MA2/E3X Ambient Cure (Fig. 8)

- 795 kcmil Drake/ACSS/MA2 (Fig 8)

- Four dead-end clamps: AFL HiTemp compression dead ends (AFL 33100 HT); AFL filled with AFL HiTemp filler compound (ACFCHT10T)

- Two suspension clamps: Preformed Line Products Thermolign suspension clamps (AGS-5130HT) 

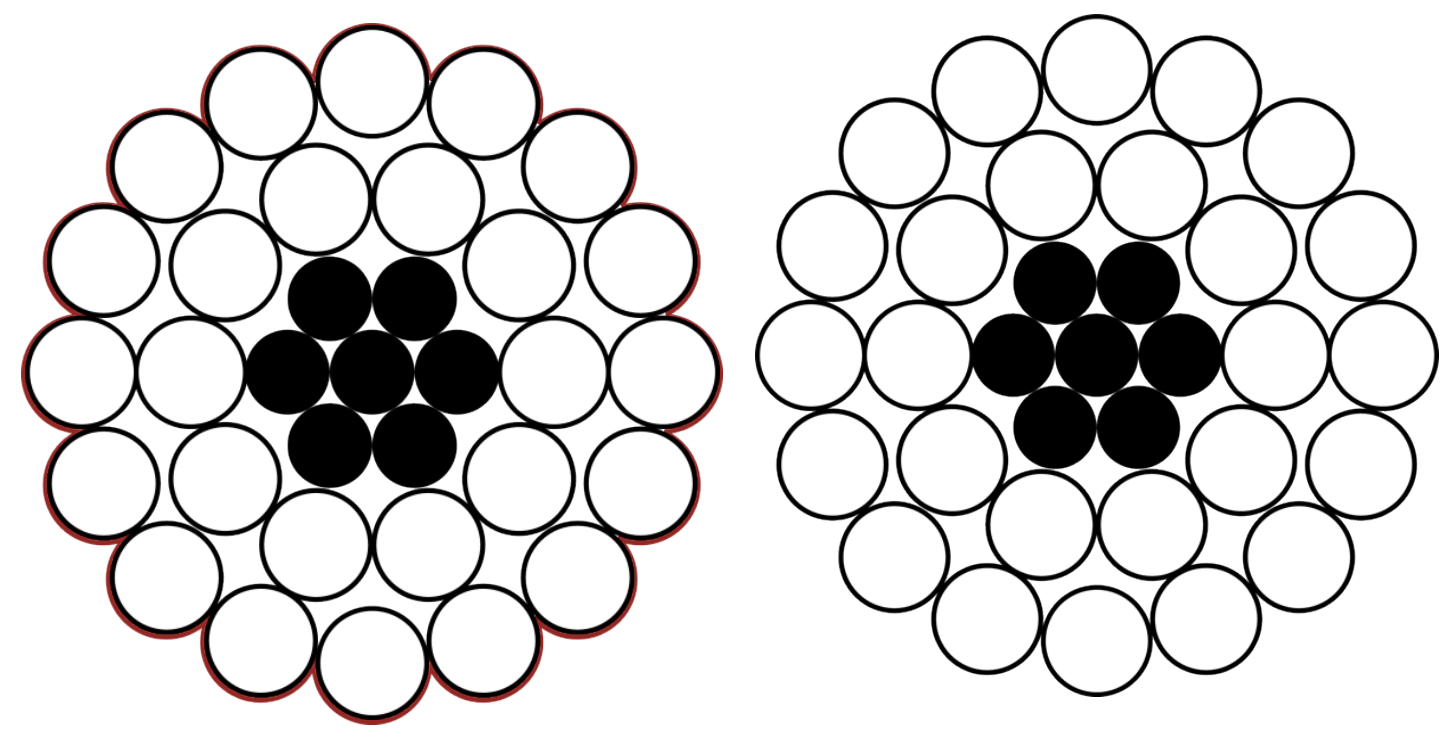

Fig. 8. Drake/ACSS/MA2/E3X (left) and Drake/ACSS/MA2 (right).

dc power source. A $2.25 \mathrm{MW}$ controllable dc power source provides current to the test conductor. The power source is fed by a $13.8 \mathrm{kV} / 4,160 \mathrm{~V}$ transformer. The power supply is rated to change the current from 0 to 5,000 Adc and voltage from 0 to $400 \mathrm{Vdc}$. A manual limit can be set to prevent the power supply from operating above a specified current. A conductor temperature limit, based on the real-time measured conductor temperature, can be set to prevent damage to the conductor and accessories.

Instrumentation. During testing, the following instrumentation elements and measurements provide feedback information for the control system.

- Type T thermocouples placed directly on the conductor surface (Figs. 9 and 10).

- Conductor tension measurements taken by two load cells located on the transmission poles adjacent to the dc power source. The load cell is a transducer that converts the measured force into an electrical signal (Fig. 11).

- Conductor clearance, or sag, determined with a laser range finder located at the midpoint of the first conductor span just above ground level. A reflective plate (laser target) is attached to the conductor directly above the laser to measure vertical displacement.

- The current passed through the conductor and the voltage drop determined by the measured output of the de power supply.

- A weather station located on the top of the first pole provides ambient temperature, wind speed, wind direction, and solar radiation.

- A net radiation sensor measures the conductor temperature due to ambient conditions. 


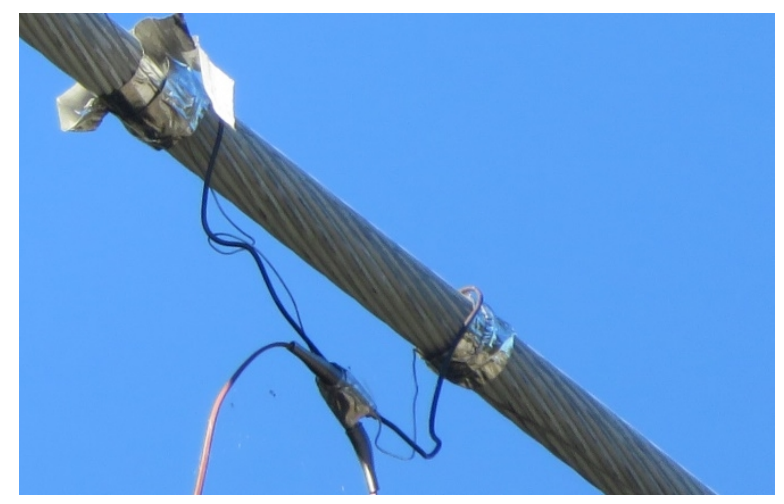

Fig. 9. Thermocouple attachment.

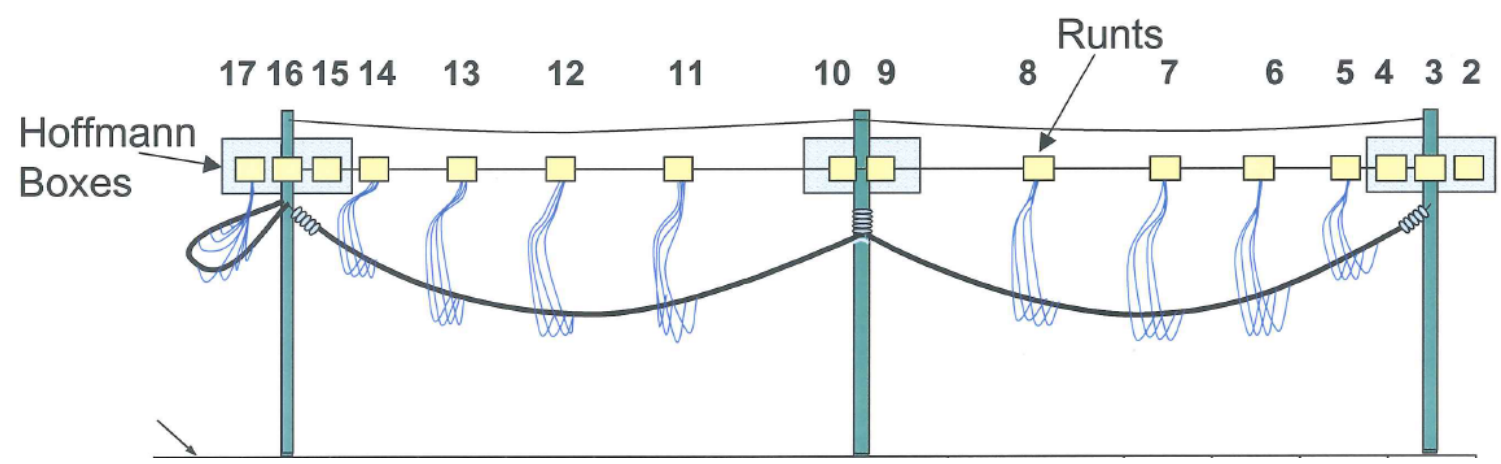

Fig. 10. Thermocouple locations (eight COYOTE runts and three pole-mount enclosures connected by two fiber networks).



Fig. 11. Load cell. 
Data acquisition and control system. A LabVIEW-based data acquisition and control system is used to capture PCAT data and provide the appropriate control to maintain test set points. Currently this system is being upgraded to include more functionality including visualization, historical trends, etc.

\section{INSTALLATION}

Installation services were provided by Pike Construction. General Cable provided one reel containing 2,000 ft of Drake/ACSS/MA2 and one reel containing 2,000 ft of Drake/ACSS/MA2/E3X produced at General Cable's Williamsport PA manufacturing facility for this installation. The reels were inspected before installation, and no damage was found to either the surface coating or the conductor.

The conductors were installed using a combination letoff / bullwheel tensioner to provide back tension on the conductor to maintain clearance from the ground. Figure 12 shows this setup.



Fig.13. The E3X coated conductor was installed on the tree side of the line, while the uncoated conductor was installed on the road side of the line.

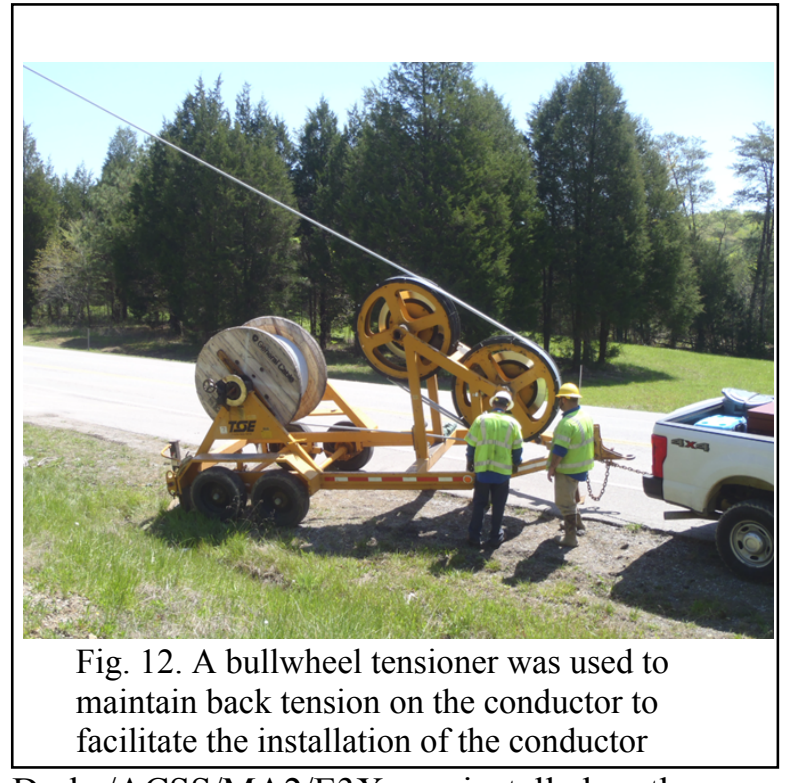

Drake/ACSS/MA2/E3X was installed on the tree side of the poles while standard Drake/ACSS/MA2 was installed on the road side. Figure 13 shows context of treeside and roadside. Roadside is the closest to Old Bethel Valley Rd which is shown.

The individual conductors were sagged and clipped in at the same tension to ensure identical installation conditions. The conductors were electrically terminated with compression dead ends using standard installation practices. They were then jumper at the last tower to join the circuit. The outer surfaces of the conductor ends were prepared by wire brushing to remove the coating and aluminum oxide before insertion in the compression dead ends. Wire brushing was not necessary for the suspension clamps. 


\section{TEST PLAN}

The conductors are being tested according to the following test plan.

1. Constant current tests. Current tests will be performed at the temperatures shown in Table 1. For each test, the current will be held constant for about 24 hours. The currents shown in Table 1 are approximate; the actual currents to be used will be calculated based on local weather conditions at the time of the tests and IEEE 738, assuming nighttime weather conditions (no sun) with no wind.

Table 1. Current and Approximate Temperatures

\begin{tabular}{cc}
\hline $\begin{array}{c}\text { Target Temperature Drake/ACSS/MA2 } \\
\left({ }^{\circ} \mathbf{C}\right)\end{array}$ & $\begin{array}{c}\text { Approximate Current } \\
(\mathbf{A})^{\boldsymbol{a}}\end{array}$ \\
\hline 90 & 900 \\
100 & 1,000 \\
110 & 1,100 \\
150 & 1,200 \\
\hline
\end{tabular}

${ }^{a}$ Adjusted for local weather conditions on day of test.

2. Current thermal/mechanical cycling tests. The conductor will be thermally and mechanically cycled 500 times. The duration of each cycle will be 3 hours. For each cycle, with the conductor at ambient temperature, a dc current will be applied for 1.5 hours to heat the conductor. During this time period, a constant current will be applied for 30 to 45 minutes to quickly heat the conductor to its rated operating temperature, and then the current will be modulated for the remainder of the 1.5 hours to maintain the set operating temperature of the coated conductor. At the end of the 1.5 hours, the current will be shut off and the conductor allowed to cool back to near ambient temperature for 1.5 hours. Eight thermal cycles can be completed in a single day, and 500 thermal cycles can be completed in approximately 64 days of testing.

\section{TEST RESULTS}

The duration of the entire testing was about five months, from November $2^{\text {nd }}, 2018$ to March $30^{\text {th }}, 2019$. The constant current test was conducted first with variations of current amplitude values. The thermal/mechanical cycling test followed, and close to 500 thermal $/ \mathrm{mechanical} \mathrm{cycles} \mathrm{in} \mathrm{total} \mathrm{were}$ applied to the two conductors. There are also days when no current was applied and the conductor temperatures were measured under the ambient conditions. The calendar in Fig. A1 shows what specific test was conducted on each day during the whole testing. 

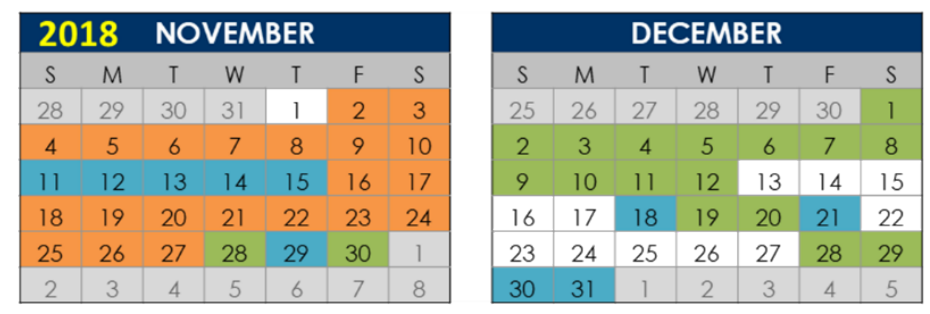

Constant current test

Thermal/Mechanical cycling

No-current temp. reading


Fig. A1 Calendar of the entire duration of the testing

\subsection{CONSTANT CURRENT TESTS}

Constant current was applied to the line and the temperature was monitored on both conductors. Table 2 lists the dates on which the test were conducted and the currents were applied. Figures 14-20 show the temperature values from the thermocouples installed midpoint on the spans. The data were plotted using a 30-point moving average. Each chart represents different timeframes maintaining a constant current. Each day a different maximum conductor temperature was targeted. Table 2 shows initial results of the constant current tests, and Fig. 21 shows the reduction in sag for the Drake/ACSS/E3X conductor.

Table 2 Applied current on each testing day of the constant current test

\begin{tabular}{cc|cc|cc}
\hline Date & $\begin{array}{c}\text { Applied } \\
\text { Current (A) }\end{array}$ & Date & $\begin{array}{c}\text { Applied } \\
\text { Current (A) }\end{array}$ & Date & $\begin{array}{c}\text { Applied } \\
\text { Current (A) }\end{array}$ \\
\hline $11 / 02 / 18$ & 900 & $11 / 10 / 18$ & 1200 & $11 / 23 / 18$ & 1350 \\
$11 / 03 / 18$ & $885 / 905$ & $11 / 16 / 18$ & 1300 & $11 / 24 / 18$ & 1350 \\
$11 / 04 / 18$ & $900 / 1000$ & $11 / 17 / 18$ & 1300 & $11 / 25 / 18$ & 1350 \\
$11 / 05 / 18$ & 1000 & $11 / 18 / 18$ & 1300 & $11 / 26 / 18$ & $1350 / 1750$ \\
$11 / 06 / 18$ & 1000 & $11 / 19 / 18$ & 1200 & $11 / 27 / 18$ & 1500 \\
$11 / 07 / 18$ & 1100 & $11 / 20 / 18$ & $1200 / 1400$ & $11 / 28 / 18$ & 1500 \\
$11 / 08 / 18$ & 1000 & $11 / 21 / 18$ & 1350 & & \\
$11 / 09 / 18$ & $1000 / 1200$ & $11 / 22 / 18$ & 1350 & & \\
\hline
\end{tabular}




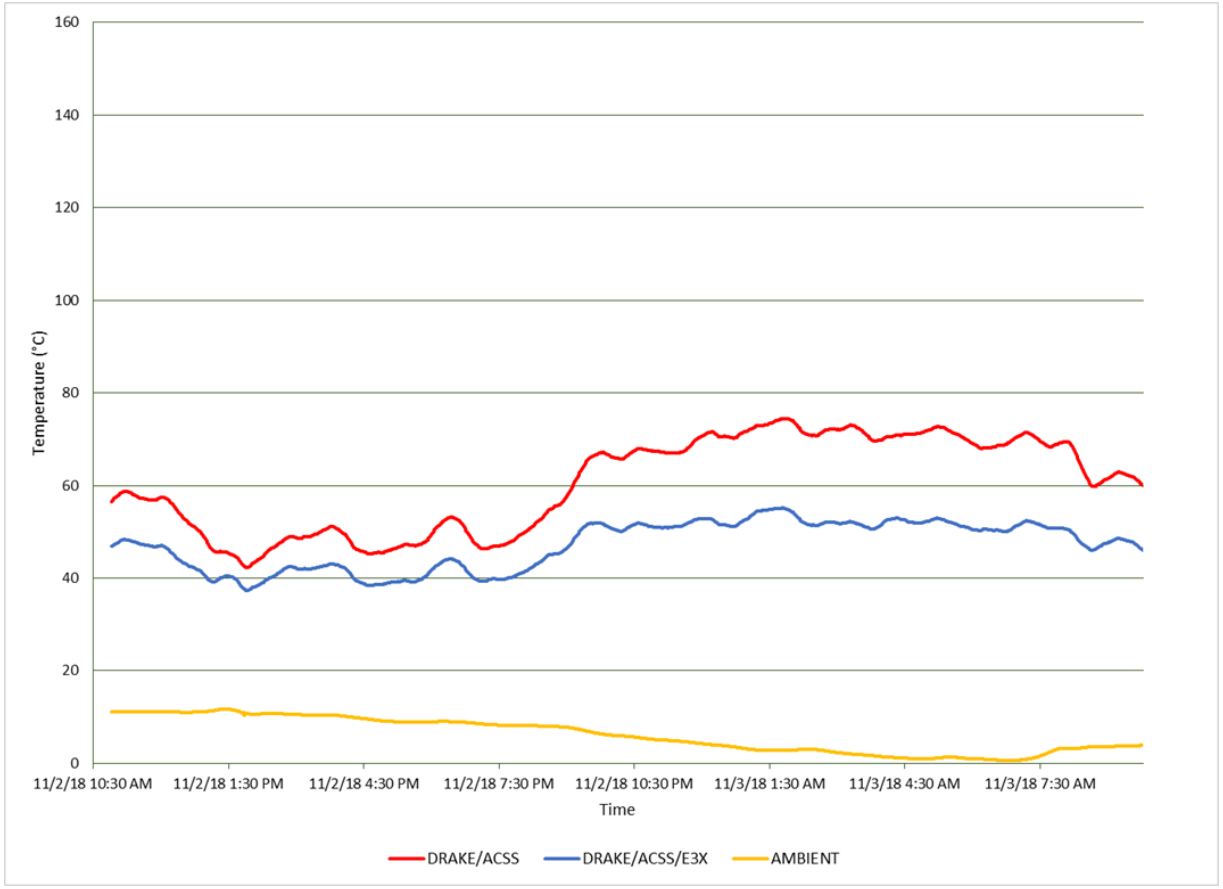

Fig. 14. Temperature comparison of Drake/ACSS and Drake/ACSS /E3X at 890 A (channel 11, midspan).

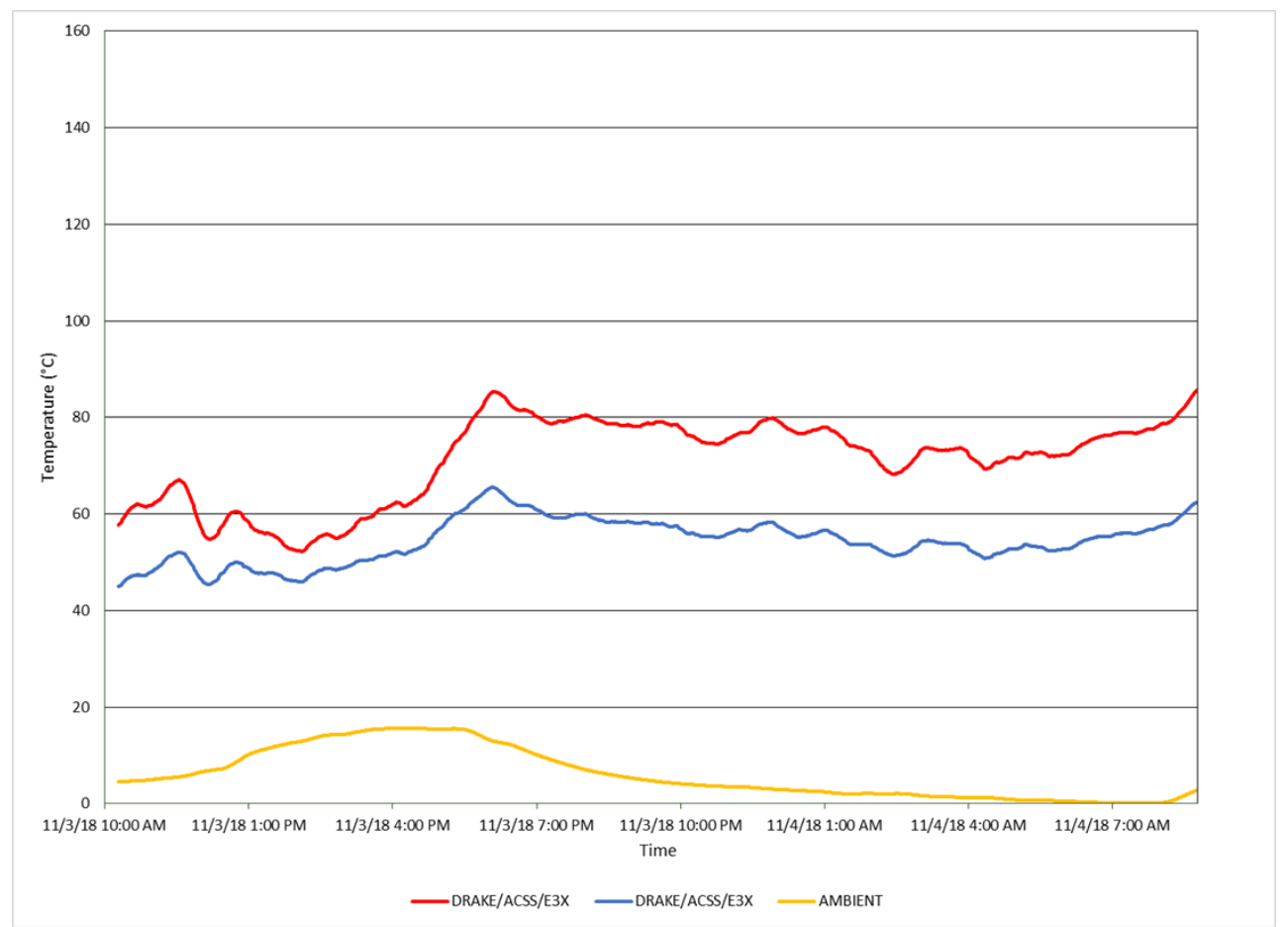

Fig. 15. Temperature comparison of Drake/ACSS and Drake/ACSS /E3X at 905 A (channel 11, midspan). 




Fig.16. Temperature comparison of Drake/ACSS and Drake/ACSS /E3X at 995 A (channel 11, midspan).

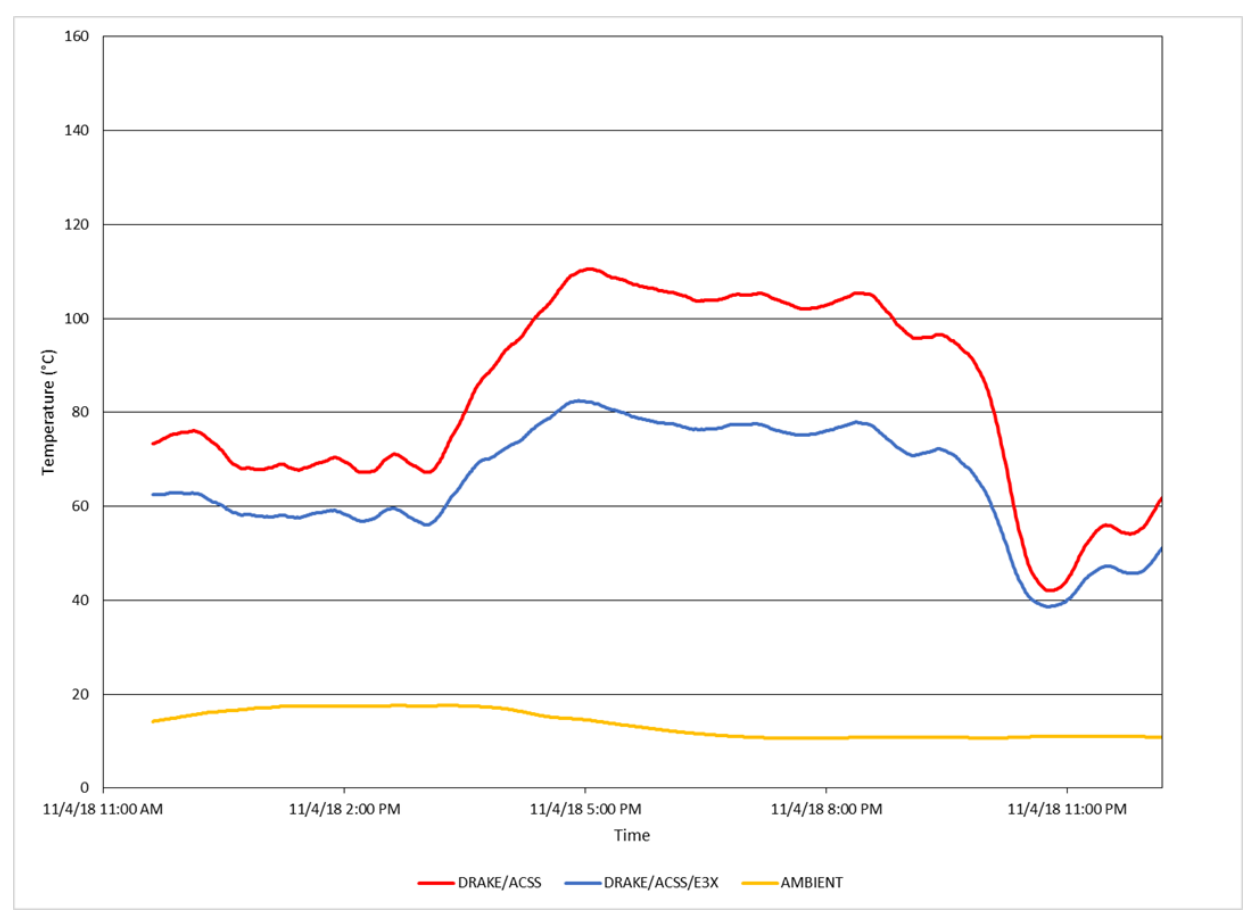

Fig.17. Temperature comparison of Drake/ACSS and Drake/ACSS /E3X at 1000 A (channel 11, midspan). 


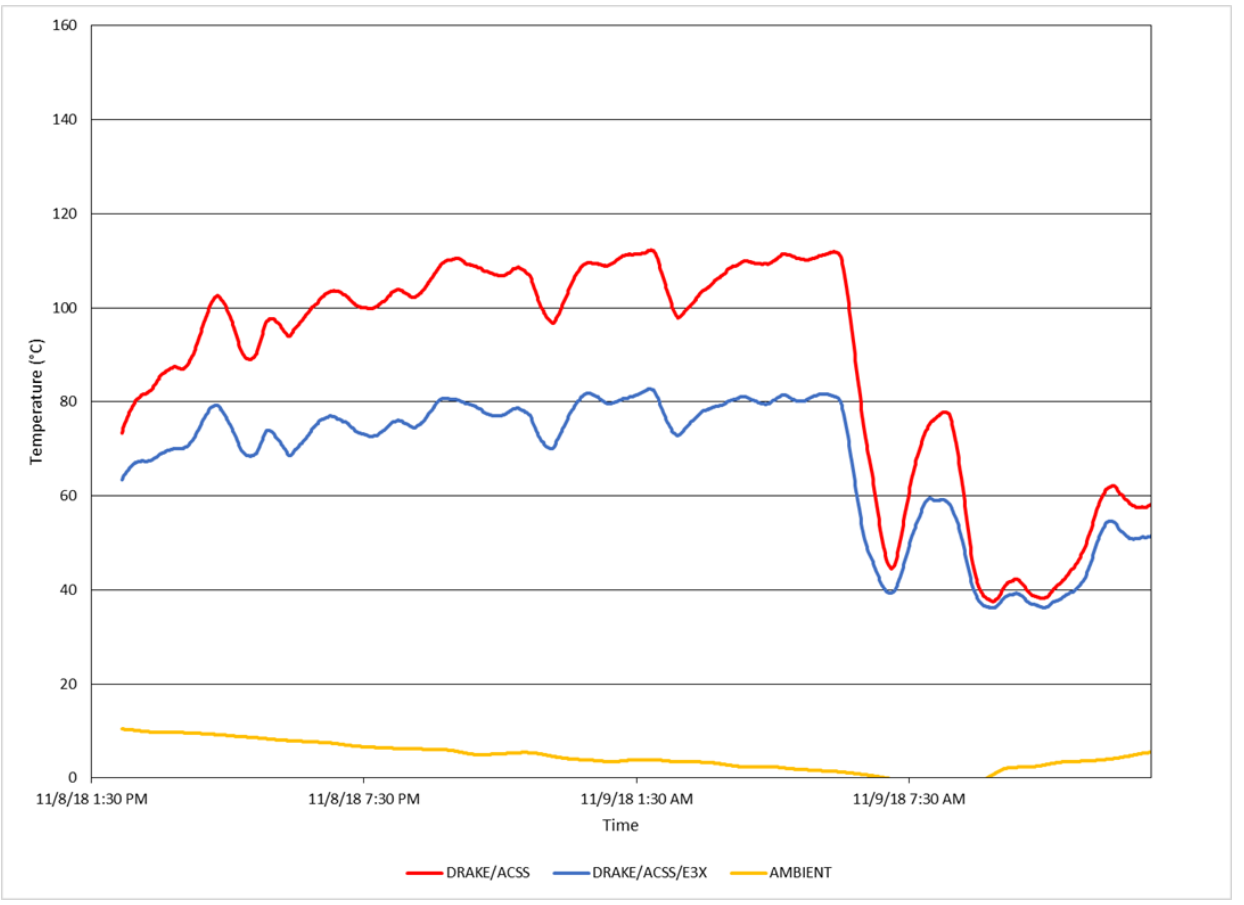

Fig.18. Temperature comparison of Drake/ACSS and Drake/ACSS /E3X at 1015 A (channel 11, midspan).

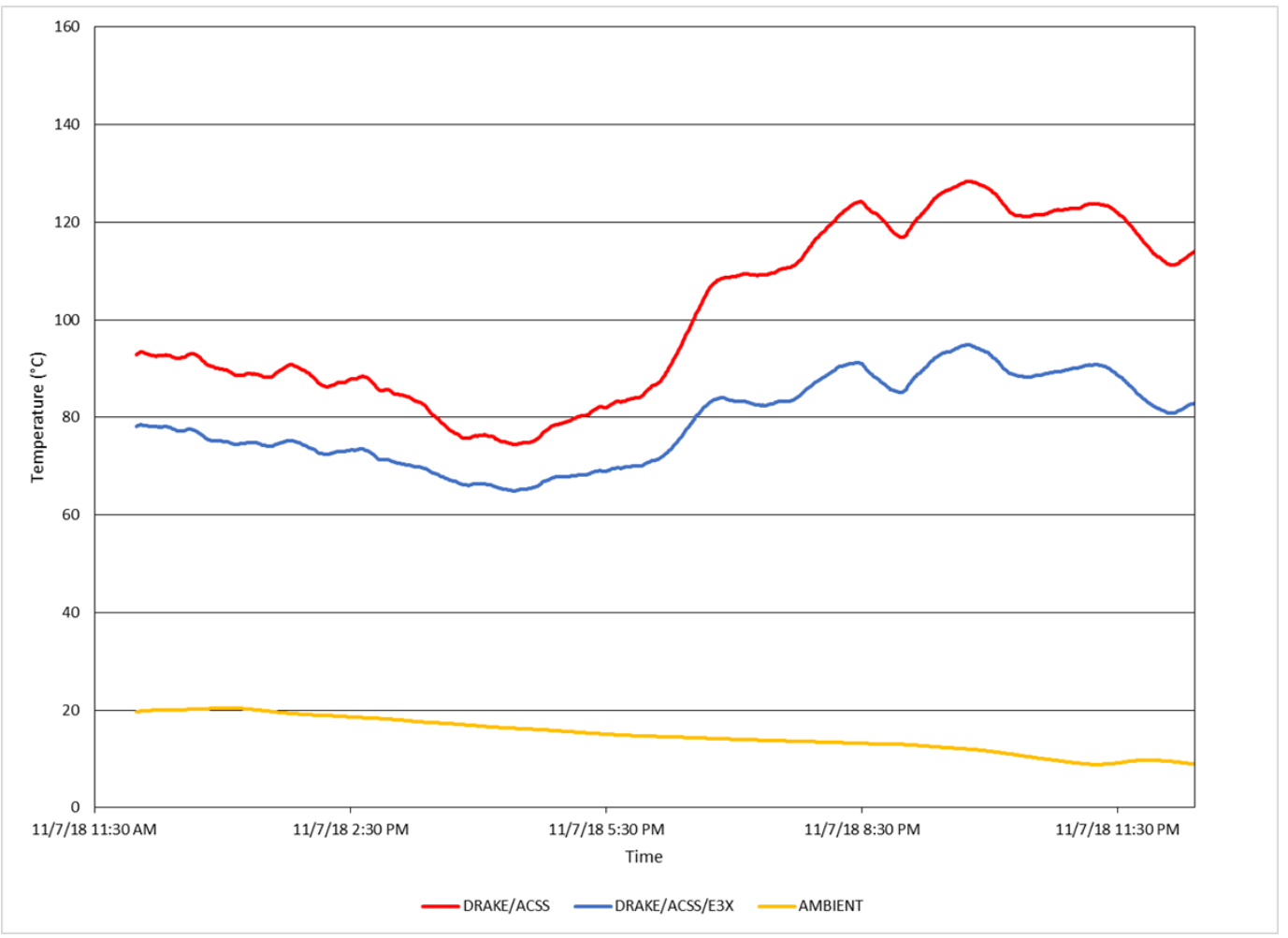

Fig. 19. Temperature comparison of Drake/ACSS and Drake/ACSS /E3X at 1115 A (channel 11, midspan). 




Fig. 20. Temperature comparison of Drake/ACSS and Drake/ACSS /E3X at 1190 A (channel 11, midspan). 


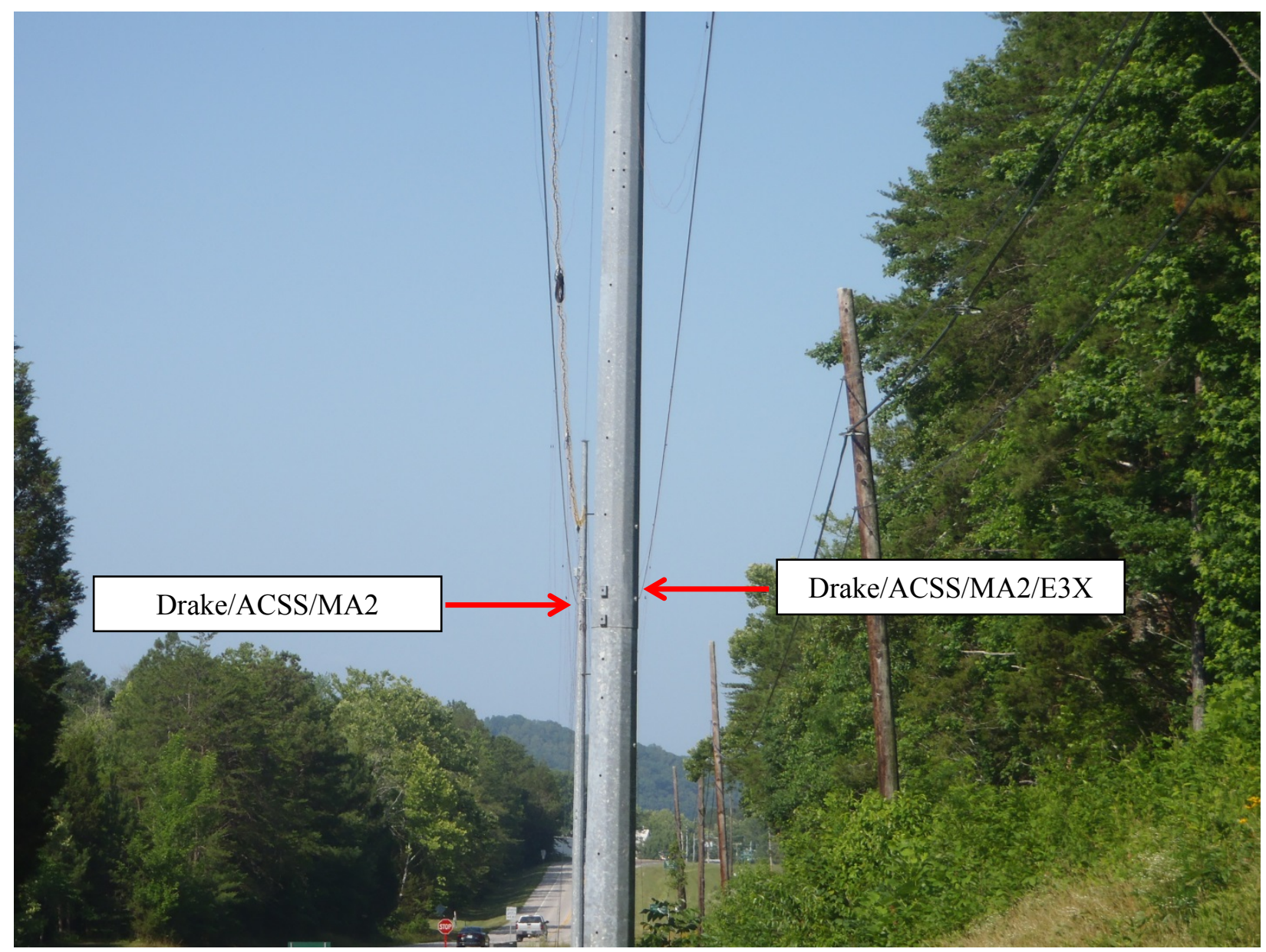

Fig. 21. A reduction in sag (indicating lower temperature) can be seen on the Drake/ACSS/MA2/E3X conductor.

\subsection{CURRENT THERMAL/MECHANICAL CYCLING TESTS}

There were about 480 thermal/mechanical cycles in total accumulatively applied to the two conductors during the test. Variable current was applied to both conductors to achieve a constant temperature on the E3X coated conductor. Temperature was monitored on both conductors to evaluate how the temperature increases of the non-coated conductor while the E3X maintains around the set point. Fig. 22 compares the temperature values from the beginning and ending of the cyclic testing. The current loading was automatically adjusted to maintain a set point of $130^{\circ} \mathrm{C}$ temperature on the coated conductor. 


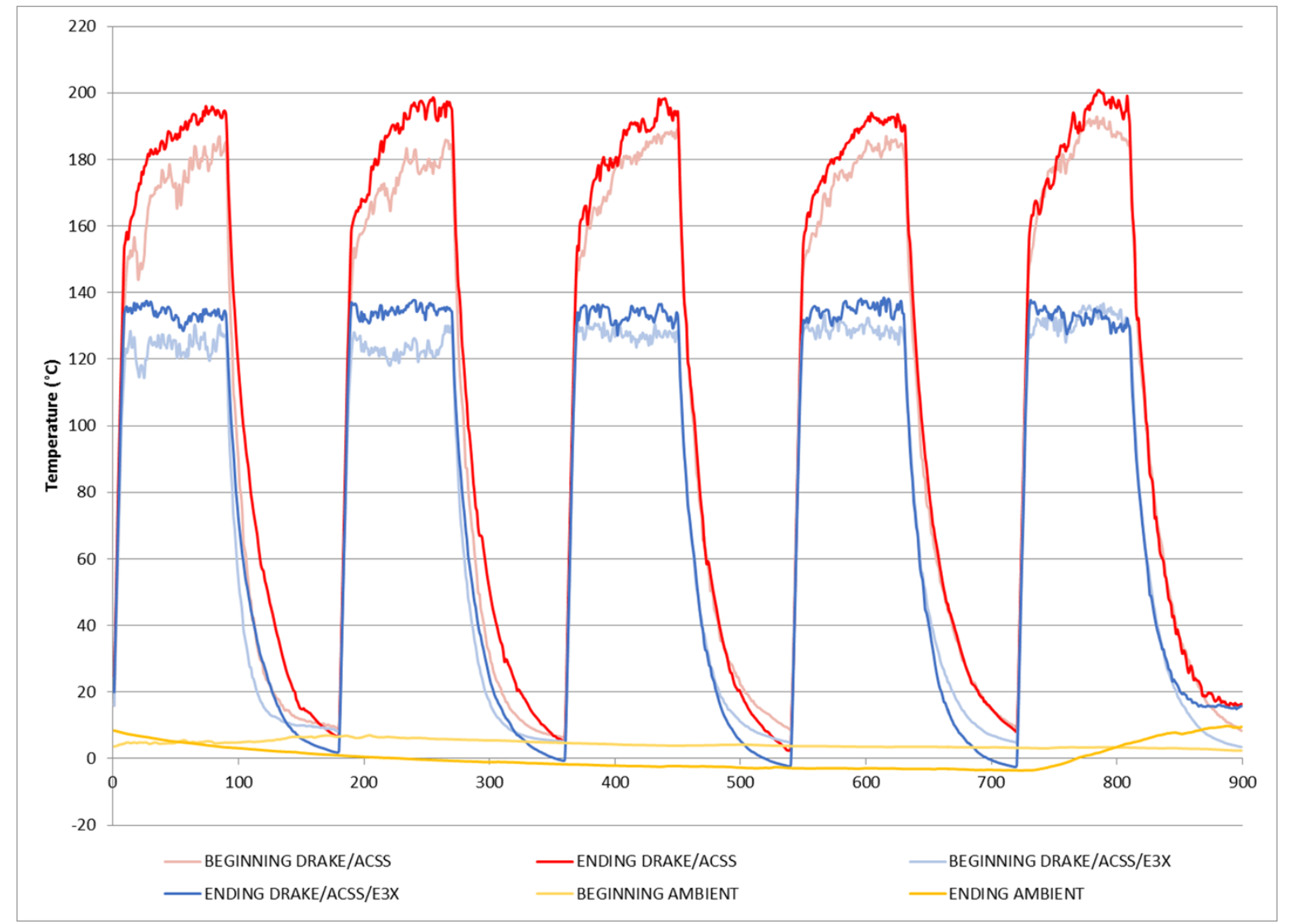

Fig. 22. Temperature comparison of DRAKE/ACSS and DRAKE/ACSS/E3X with modulated current based on the E3X conductor set temperature (channel 11, midspan) The chart overlays the response temperature at the beginning of the testing with the response temperatures of the testing at the end of the 500 cycles.

The knee point of the tension-temperature curves of the conductors are also evaluated in order to check aging effect of the thermal cycles on the mechanical strength of the conductors. The conductor tension readings are plotted against their temperature readings to show the strength change over the cycles of conductor temperature rise and drop. Fig. 22A1 shows the curves for the two conductors at the very beginning of the cycling test, and Fig. 22A 2 for the curves at the end of the test. 


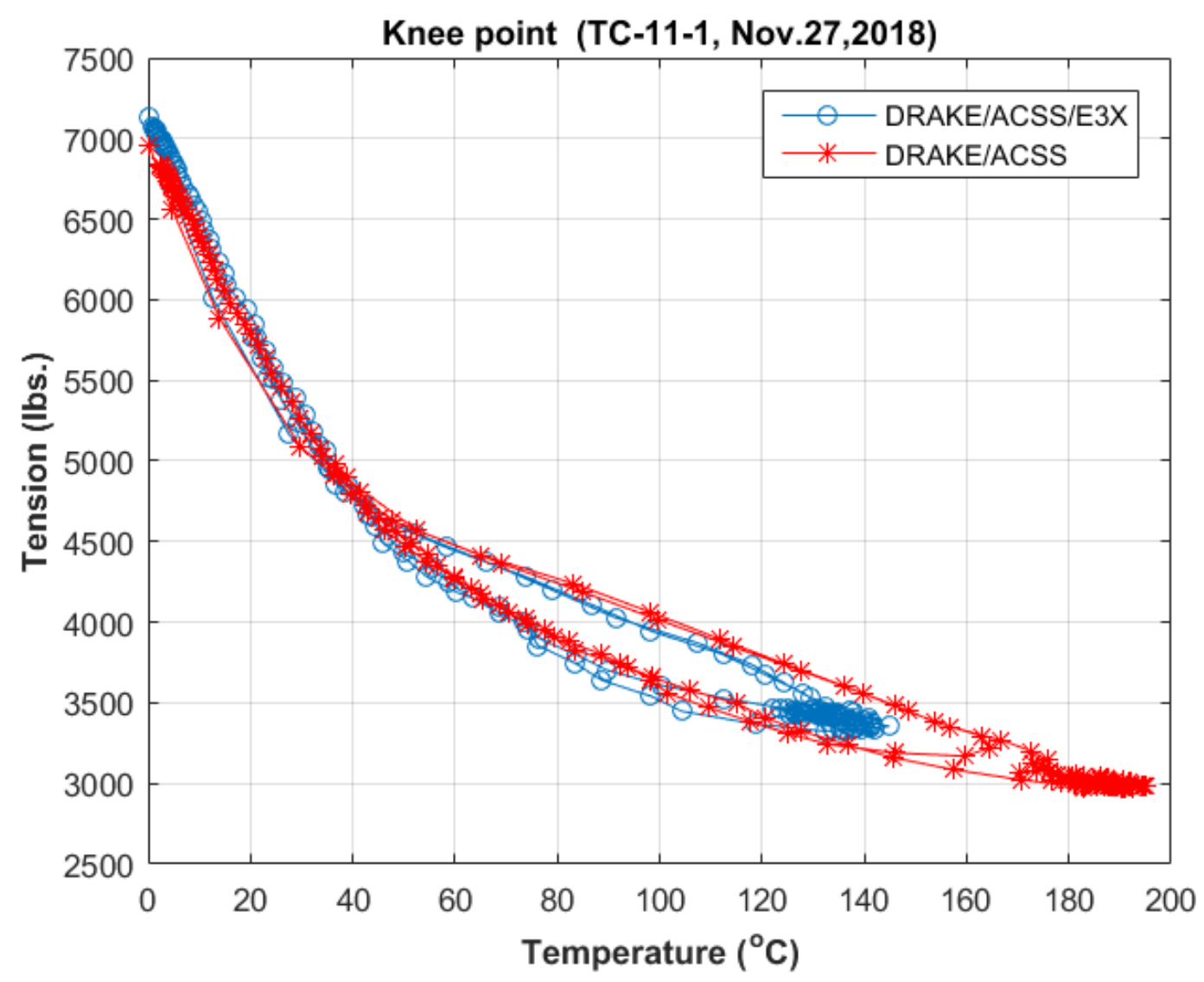

Fig. 22A1. Tension-temperature curves of the two conductors at the beginning of the thermal cycling test

Before the thermal cycling test, the mechanical characteristics of the two conductors were very similar to each other. The only difference shown in Fig. 22A1 is that the curve for ACSS/E3X is shorter than that for the one without the coating, because the coated conductor had lower temperature during the cycles. The tension-temperature curve follows different traces when the temperature rises and drops, forming a hysteresis loop-like pattern. The loop covers a temperature range from $\sim 50^{\circ} \mathrm{C}$ to $\sim 180^{\circ} \mathrm{C}$ for the ACSS conductor and from $\sim 50^{\circ} \mathrm{C}$ to $\sim 130^{\circ} \mathrm{C}$ for the $\mathrm{ACSS} / \mathrm{E} 3 \mathrm{X}$ conductor.

The ACSS conductor has a steel core around which are wound fully annealed aluminum wire strands As a result, the entire conductor is mostly or completely supported by the steel core, and the tension characteristics of ACSS conductors are governed by the mechanical properties of the steel. The hysteresis pattern illustrated in Fig. 22A1 and Fig. 22A2 is characteristic of the steel core. It is also worth noting that this hysteresis pattern is not obvious for ACSR conductors, in which both the steel core and hard-drawn aluminum wires provide the support to the conductor.

The ACSS conductor has a so called "knee point" in the tension curves at which there is a transition of tension support from the aluminum and steel acting in tandem to the steel only as the conductor temperature rises. The results shown in the two figures are consistent with this knee point. 




Fig. 22A2. Tension-temperature curves of the two conductors at the end of the thermal cycling test

Fig. 22A2 shows the tension vs. temperature curves for the two conductors (Drake/ACSS/E3X and Drake/ACSS) when all the thermal cycles have been applied. It can be observed that the tensions above the knee point are similar to those before thermal cycling was applied.. At the conductor temperature of $0^{\circ} \mathrm{C}$, the initial tensions (before the cycling test) of DRAKE/ACSS and DRAKE/ACSS/E3X are both $\sim 7000 \mathrm{lb}$, while they drop to $\sim 6200 \mathrm{lb}$ and $\sim 6700 \mathrm{ls}$, respectively, after the test.

\subsection{NO CURRENT TEMPERATURE READINGS}

No current was applied to either conductor and the temperature was monitored on both conductors. Fig. 23 has a timeframe of three days with the raw data of the temperature variation. The temperature profile of both the E3X coated and the uncoated conductor are identical. Heating of the conductor would have been the result of energy absorbed by the sun. Conductor surfaces with a different coefficient of absorptivity would track at different temperatures. The chart tracks the temperature of the conductor and the ambient air temperature both through the night as well as the day time over this three day period. 


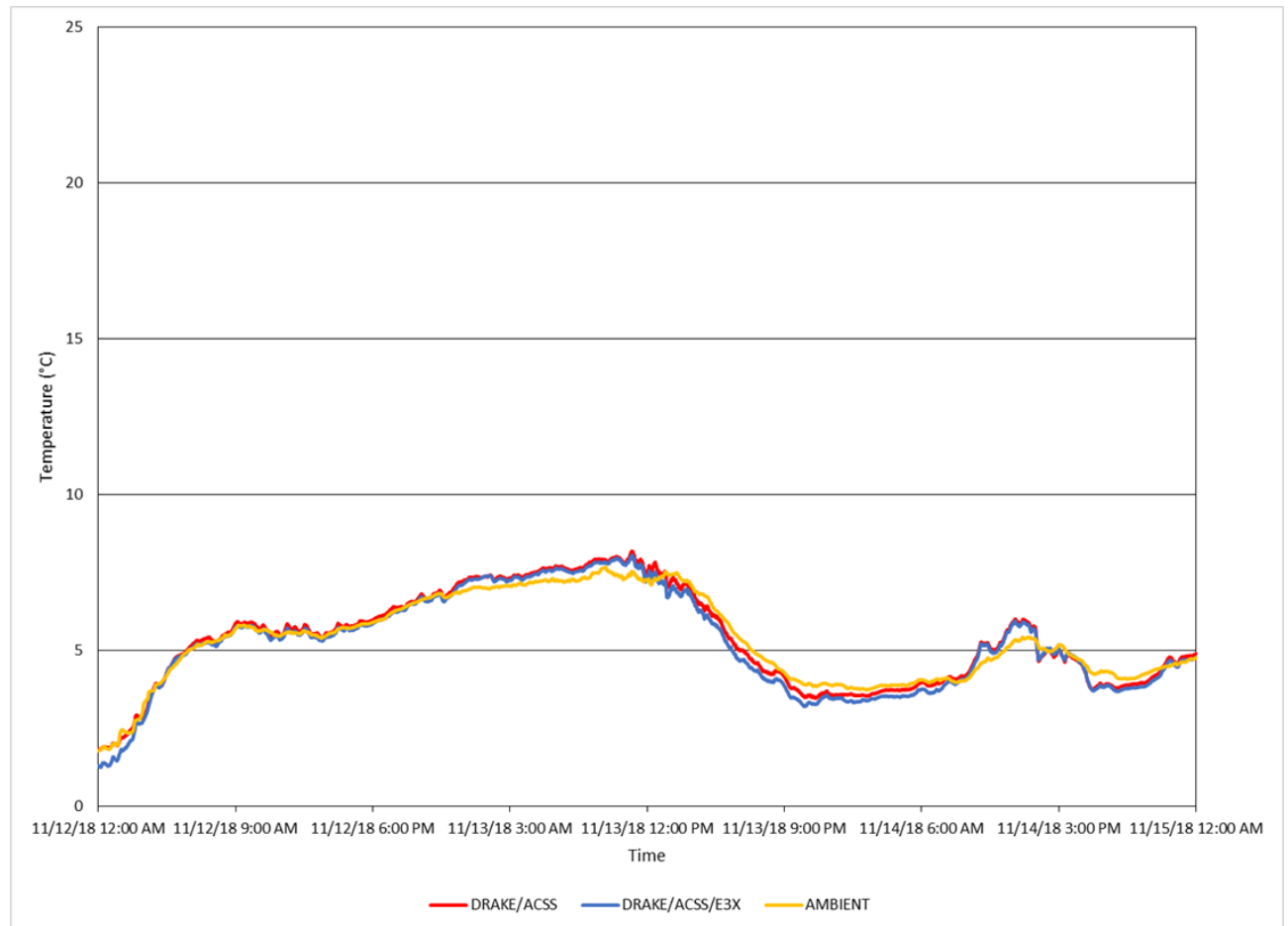

Fig. 23. Temperature comparison of DRAKE/ACSS and DRAKE/ACSS/E3X with 0 A (channel 11, midspan)

\section{SUMMARY OF OBSERVATIONS}

Drake/ACSS/MA2/E3X conductor was evaluated side by side with Drake/ACSS/MA2 (standard) conductor at PCAT under a wide range of currents over a period of time from the fourth quarter of 2018 to the first quarter of 2019. During the constant current testing, Drake/ACSS/MA2/E3X conductor showed on average an $18 \%$ to $25 \%$ reduction in conductor temperature when compared to the uncoated Drake/ACSS/MA2 conductor. This difference was observed over the uncoated conductor temperature range of $40^{\circ} \mathrm{C}$ to $140^{\circ} \mathrm{C}$. The reduction in conductor temperature for Drake/ACSS/MA2/E3X conductor increased as the current and temperature increased. Consistent with the temperature measurements, sag measurements showed that Drake/ACSS/MA2/E3X conductor had less sag than Drake/ACSS/MA2 conductor at the same operating conditions.

The cyclic aging test results demonstrated that after 500 cycles there was no apparent degradation in the performance life of the E3X coating. The apparent coefficient of emissivity and absorptivity values that affect the temperature performance of the coated conductor did not change. The average reduction in conductor temperature in the cyclic aging tests between the uncoated and coated conductor was approximately $30 \%$ at the beginning of the testing and $31 \%$ at the end. Throughout the testing the temperature of the uncoated conductor varied between $180^{\circ} \mathrm{C}$ and $195^{\circ} \mathrm{C}$. Throughout the cyclic testing the temperature of the coated conductor varied between 130 and $135 \mathrm{C}$.

For conductors left sitting without any current loaded on them, the temperature gain from solar radiation heating appeared to have the same effect on both the coated conductor as well as the uncoated conductor. Because the temperature response was the same it would be assumed that the coefficient of absorptivity of the E3X coating material matched that of the uncoated conductor's specular (shiny) surface. 


\section{APPENDIX A. CONTROL SYSTEM FOR THE POWERLINE CONDUCTOR ACCELERATED TEST FACILITY}

The Oak Ridge National Laboratory Powerline Conductor Accelerated Test facility has had a long history of testing conductors and acquiring detailed measurements for conductors in the field. The current system, which has been in place for more than 10 years, is described here, along with revitalization efforts to modernize the system. Originally the system was controlled by a set of codes in Visual Basic that ran during the test on a desktop computer. Over time, issues have arisen related to requests for more rapid data acquisition and improved system control. Updating parameters and controls has been complicated in the past by the need for detailed knowledge of the original coding and the need to take the system offline to update the parameters. Figure A.1 shows the current data acquisition system, which can accommodate up to 128 thermocouple measurements, current and voltage measurements, conductor sag, conductor tension, and weather conditions.

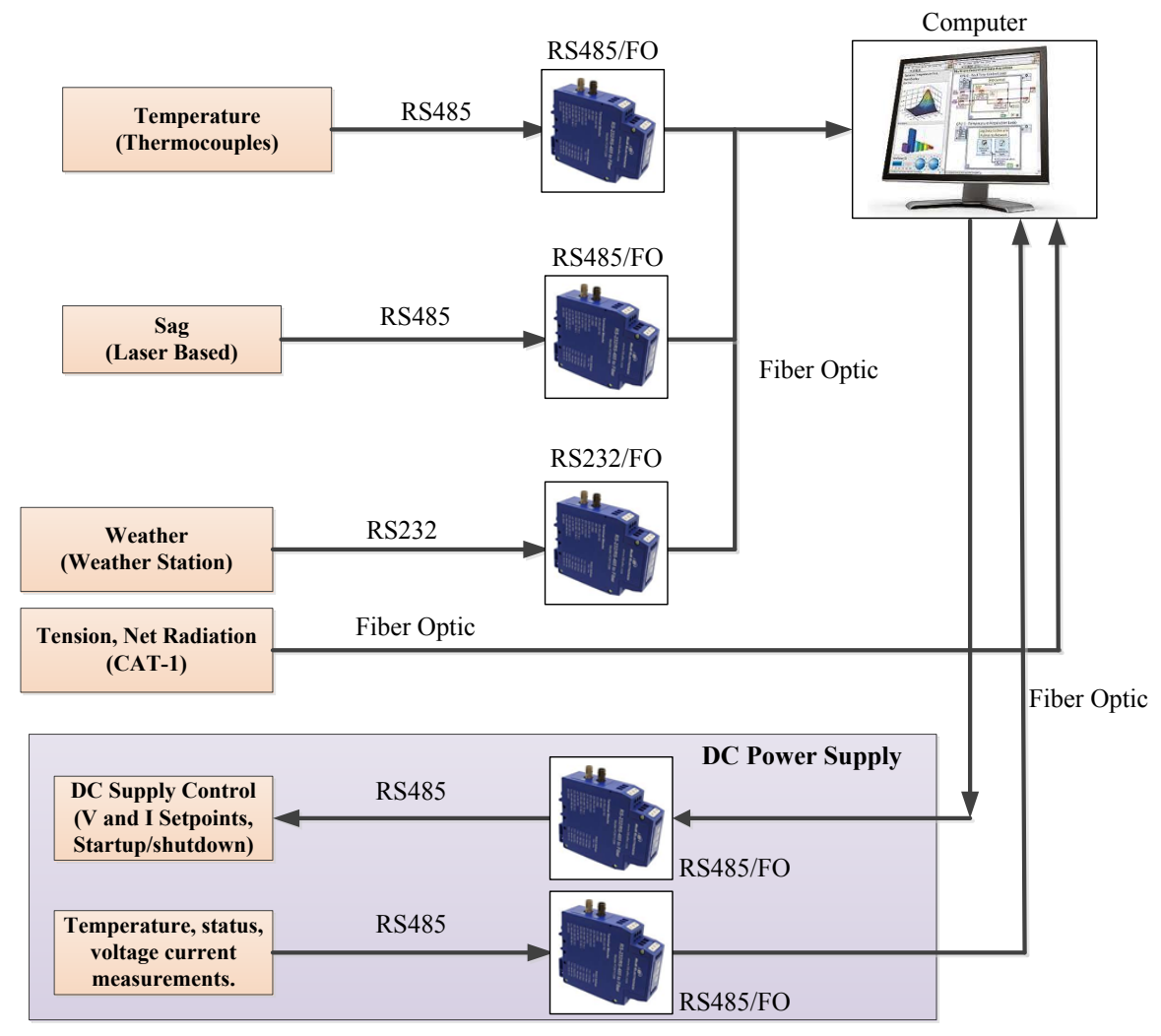

Fig. A.1. Current operating system for the Powerline Conductor Accelerated Test facility.

As part of test system upgrade efforts, a new data acquisition system is being deployed. The biggest change is transitioning the system software from Visual Basic to LabVIEW. To design the system in the most versatile way possible, a design known as "actor framework" has been chosen for the LabVIEW software integration. This type of system will permit asynchronous, parallel measurement, processing, and control. It also allows seamless integration of additional measurements. Figure A.2 shows the proposed new system design. 


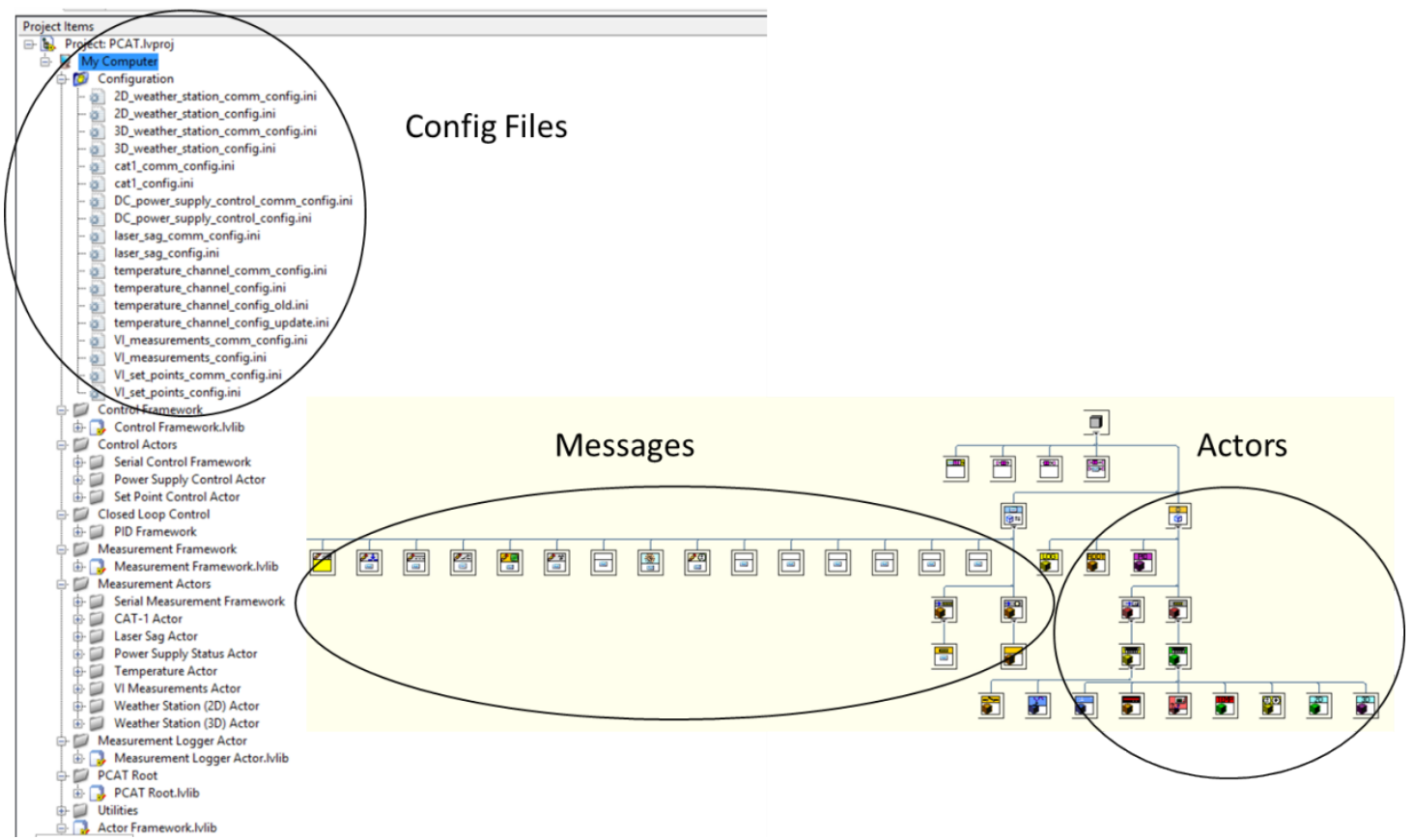

Fig. A.2. Proposed design for new LabVIEW-based system.

This transition will be accompanied by installation of additional sensors and a thermal camera for realtime images of ongoing tests. This will also include the addition of image processing to gain additional insight into the temperature and sag of conductors. 


\section{APPENDIX B. THERMOCOUPLE CHANNELS AND LOCATIONS}

Table B.1. Thermocouple Attachment Channels and Locations

\begin{tabular}{|c|c|c|c|c|c|}
\hline Channel & Location & Conductor & Channel & Location & Conductor \\
\hline $2-1 \mathrm{~T}$ & First Tower & Standard & $11-1 \mathrm{~T}$ & $750 \mathrm{ft}$ & Standard \\
\hline $2-2 \mathrm{~T}$ & First Tower & Standard & $11-2 \mathrm{~T}$ & $750 \mathrm{ft}$ & Standard \\
\hline $2-3 R$ & First Tower & $\mathrm{E} 3 \mathrm{X}$ & $11-3 R$ & $750 \mathrm{ft}$ & E3X \\
\hline $2-4 R$ & First Tower & E3X & $11-4 R$ & $750 \mathrm{ft}$ & E3X \\
\hline $3-1 \mathrm{~T}$ & First Tower & Standard & $12-1 \mathrm{~T}$ & $900 \mathrm{ft}$ (midspan) & Standard \\
\hline $3-2 \mathrm{~T}$ & First Tower & Standard & $12-2 \mathrm{~T}$ & $900 \mathrm{ft}$ (midspan) & Standard \\
\hline $3-3 R$ & First Tower & $\mathrm{E} 3 \mathrm{X}$ & $12-3 R$ & $900 \mathrm{ft}$ (midspan) & E3X \\
\hline $3-4 R$ & First Tower & E3X & $12-4 R$ & $900 \mathrm{ft}$ (midspan) & $\mathrm{E} 3 \mathrm{X}$ \\
\hline $5-1 \mathrm{~T}$ & $150 \mathrm{ft}$ & Standard & $13-1 \mathrm{~T}$ & $900 \mathrm{ft}$ (midspan) & Standard \\
\hline $5-2 \mathrm{~T}$ & $150 \mathrm{ft}$ & Standard & $13-2 \mathrm{~T}$ & $900 \mathrm{ft}$ (midspan) & Standard \\
\hline $5-3 R$ & $150 \mathrm{ft}$ & $\mathrm{E} 3 \mathrm{X}$ & $13-3 R$ & $900 \mathrm{ft}$ (midspan) & E3X \\
\hline $5-4 R$ & $150 \mathrm{ft}$ & E3X & $13-4 R$ & $900 \mathrm{ft}$ (midspan) & E3X \\
\hline $6-1 \mathrm{~T}$ & $300 \mathrm{ft}$ (midspan) & Standard & $14-1 \mathrm{~T}$ & $1050 \mathrm{ft}$ & Standard \\
\hline $6-2 \mathrm{~T}$ & $300 \mathrm{ft}$ (midspan) & Standard & $14-2 \mathrm{~T}$ & $1050 \mathrm{ft}$ & Standard \\
\hline $6-3 R$ & $300 \mathrm{ft}$ (midspan) & E3X & $14-3 R$ & $1050 \mathrm{ft}$ & E3X \\
\hline $6-4 \mathrm{R}$ & $300 \mathrm{ft}$ (midspan) & E3X & $14-4 \mathrm{R}$ & $1050 \mathrm{ft}$ & $\mathrm{E} 3 \mathrm{X}$ \\
\hline $7-1 \mathrm{~T}$ & $300 \mathrm{ft}$ (midspan) & Standard & $15-5 \mathrm{~T}$ & Third Tower & Standard \\
\hline $7-2 \mathrm{~T}$ & $300 \mathrm{ft}$ (midspan) & Standard & $15-6 \mathrm{~T}$ & Third Tower & Standard \\
\hline $7-3 R$ & $300 \mathrm{ft}$ (midspan) & E3X & $15-7 R$ & Third Tower & E3X \\
\hline $7-4 \mathrm{R}$ & $300 \mathrm{ft}$ (midspan) & $\mathrm{E} 3 \mathrm{X}$ & $15-8 \mathrm{R}$ & Third Tower & E3X \\
\hline $8-1 \mathrm{~T}$ & $450 \mathrm{ft}$ & Standard & $16-5 \mathrm{~T}$ & Third Tower & Standard \\
\hline $8-2 \mathrm{~T}$ & $450 \mathrm{ft}$ & Standard & $16-6 \mathrm{~T}$ & Third Tower & Standard \\
\hline $8-3 R$ & $450 \mathrm{ft}$ & E3X & $16-7 \mathrm{R}$ & Third Tower & E3X \\
\hline $8-4 \mathrm{R}$ & $450 \mathrm{ft}$ & E3X & $16-8 \mathrm{R}$ & Third Tower & E3X \\
\hline $10-1 \mathrm{~T}$ & Second Tower & Standard & & & \\
\hline $10-2 \mathrm{~T}$ & Second Tower & Standard & & & \\
\hline $10-3 R$ & Second Tower & E3X & & & \\
\hline $10-4 R$ & Second Tower & E3X & & & \\
\hline
\end{tabular}

Standard $=$ Drake/ACSS/MA2; E3X $=$ Drake/ACSS/MA2/E3X. 
